\title{
Electron Spin Resonance Spectra of some Paramagnetic Hydride Complexes of Niobium(IV) and Tantalum(IV)
}

\author{
J. BARRIE RAYNOR* \\ Department of Chemistry, The University, Leicester LE1 7RH, U.K.
}

ALFRED P.SATTELBERGER* ${ }^{\dagger}$ and MELVIN L. LUETKENS, Jr.

Department of Chemistry, University of Michigan, Ann Arbor, Mich. 48109, U.S.A.

Received July 2, 1985

\begin{abstract}
Frozen solution electron spin resonance spectra show that the unpaired electron is in a $d_{x^{2}}-y^{2}$ orbital on the metal in the complexes $\mathrm{TaCl}_{2} \mathrm{H}_{2}(\mathrm{dmpe})_{2}$, $\mathrm{TaCl}_{2} \mathrm{H}_{2}\left(\mathrm{PMe}_{3}\right)_{4}$ and $\mathrm{NbCl}_{2} \mathrm{H}_{2}(\mathrm{dmpe})_{2}$, (dmpe $=\mathrm{Me}_{2}$. $\mathrm{PCH}_{2} \mathrm{CH}_{2} \mathrm{PMe}_{2}$ ).
\end{abstract}

\section{Introduction}

Paramagnetic transition metal hydrides are not common and hitherto the only ones known for Group 5 were $\left(\eta^{5}-\mathrm{C}_{5} \mathrm{H}_{5}\right)_{2} \mathrm{MH}_{2}(\mathrm{M}=\mathrm{Nb}$ and $\mathrm{Ta})$ and $\mathrm{TaH}_{4}$ (dmpe) ${ }_{2}$ [1]. Recently, we have isolated the eight coordinate hydrides $\mathrm{NbCl}_{2} \mathrm{H}_{2}(\mathrm{dmpe})_{2}, \mathrm{TaCl}_{2}$ $\mathrm{H}_{2}\left(\mathrm{PMe}_{3}\right)_{4}$ and $\mathrm{TaCl}_{2} \mathrm{H}_{2}$ (dmpe $)_{2}$ [2-4]. The crystal structure of the two Ta complexes have been determined; both have virtual $C_{2}$ symmetry and are best described as distorted dodecahedral (for the $\mathrm{PMe}_{3}$ derivative) [2] and distorted square antiprismatic (for the dmpe** derivative) [3]. The ESR spectrum of each in toluene solution show well resolved hyperfine coupling to the metal and each phosphorus atom [4]. In this paper, we present a more detailed study of the ESR spectra of these hydrido complexes.

ESR studies on other eight coordinate complexes of early transition metals have only been carried out on the following species: $\left[\mathrm{Mo}\left(\mathrm{S}_{2} \mathrm{CNEt}_{2}\right)_{4}\right]^{+}$[5], $\mathrm{V}\left(\mathrm{S}_{2} \mathrm{CNEt}_{2}\right)_{4} \quad$ [6], $\mathrm{V}\left(\mathrm{Se}_{2} \mathrm{CNEt}_{2}\right)_{4} \quad$ [6], $\mathrm{Nb}\left(\mathrm{S}_{2}\right.$ $\left.\left.\mathrm{CNEt}_{2}\right)_{4}[6,8], \mathrm{Mo}(\mathrm{CN})_{8}\right]^{3} \quad[9,11,16]$, [W$\left.(\mathrm{CN})_{8}\right]^{3-}[9-12,15],\left[\mathrm{Nb}(\mathrm{CN})_{8}\right]^{4-}[9,13,14]$, $\mathrm{V}(\mathrm{dtb})_{4}(\mathrm{dtb}=$ dithiobenzoate $)[7,8], \mathrm{Nb}(\mathrm{dtb})_{4}$ [7], $\mathrm{V}(\mathrm{dta})_{4}(\mathrm{dta}=$ dithioacetate [7].

\footnotetext{
*Authors to whom correspondence should be addressed.

tPresent address: Isotope and Nuclear Chemistry Division, Los Alamos National Laboratory, Los Alamos, N.M. 87545, U.S.A.

**dmpe $=\mathrm{Me}_{2} \mathrm{PCH}_{2} \mathrm{CH}_{2} \mathrm{PMe}_{2}$.
}

\section{Experimental}

ESR spectra were recorded at X- and Q-band frequencies on a Bruker ER200D spectrometer at $77 \mathrm{~K}$. Samples for ESR measurements were prepared in an inert atmosphere box by dissolving the complexes in dry toluene [2]. Spectra were calibrated against a dpph marker.

\section{Results and Discussion}

Frozen solution spectra at $77 \mathrm{~K}$ are shown in Figs. $1-5$. Each shows hyperfine coupling to the metal $\left({ }^{93} \mathrm{Nb}, I=9 / 2,100 \% ;{ }^{181} \mathrm{Ta}, I=7 / 2,100 \%\right)$ and to four equivalent ${ }^{31} \mathrm{P}$ aioms. The spectra have approximately axial symmetry and the best fit spin Hamiltonian parameters are given in the Table I.

TABLE I. Best Fit Spin Hamiltonian Parameters

\begin{tabular}{lccc}
\hline & $\begin{array}{l}\mathrm{NbCl}_{2} \mathrm{H}_{2}- \\
\mathrm{dmpe}_{2}\end{array}$ & $\begin{array}{c}\mathrm{TaCl}_{2} \mathrm{H}_{2}- \\
(\mathrm{dmpe})_{2}\end{array}$ & $\begin{array}{c}\mathrm{TaCl}_{2} \mathrm{H}_{2}- \\
\left(\mathrm{PMe}_{3}\right)_{4}\end{array}$ \\
\hline$g_{\|}$ & 1.994 & 1.970 & 1.950 \\
$g_{\perp}\left(\times 10^{-4} \mathrm{~cm}^{-1}\right)$ & 1.96 & 1.99 & 1.97 \\
$A_{\|}\left(\times 10^{-4} \mathrm{~cm}^{-1}\right)$ & 58 & 150 & 170 \\
$A_{\perp}\left(\times 10^{-4} \mathrm{~cm}^{-1}\right)$ & 81 & 99 & 107 \\
$P\left(\times 10^{-4}\right.$ & 0.97 & 1.80 & 70 \\
$K$ & 25 & 25 & 35 \\
$A\left({ }^{31} \mathrm{P}\right) / G$ & & & \\
\hline
\end{tabular}

Measurements carried out at Q-band were helpful in showing that the spread of the spectra was the same as at X-band. This shows that the outermost absorptions arise from the same $g$ value and set of hyperfine lines. Thus the largest hyperfine coupling and its associated $g$ value can be unambiguously assigned. For the two tantalum complexes, this $g$ value is the lowest, and coupled with a large hyper- 


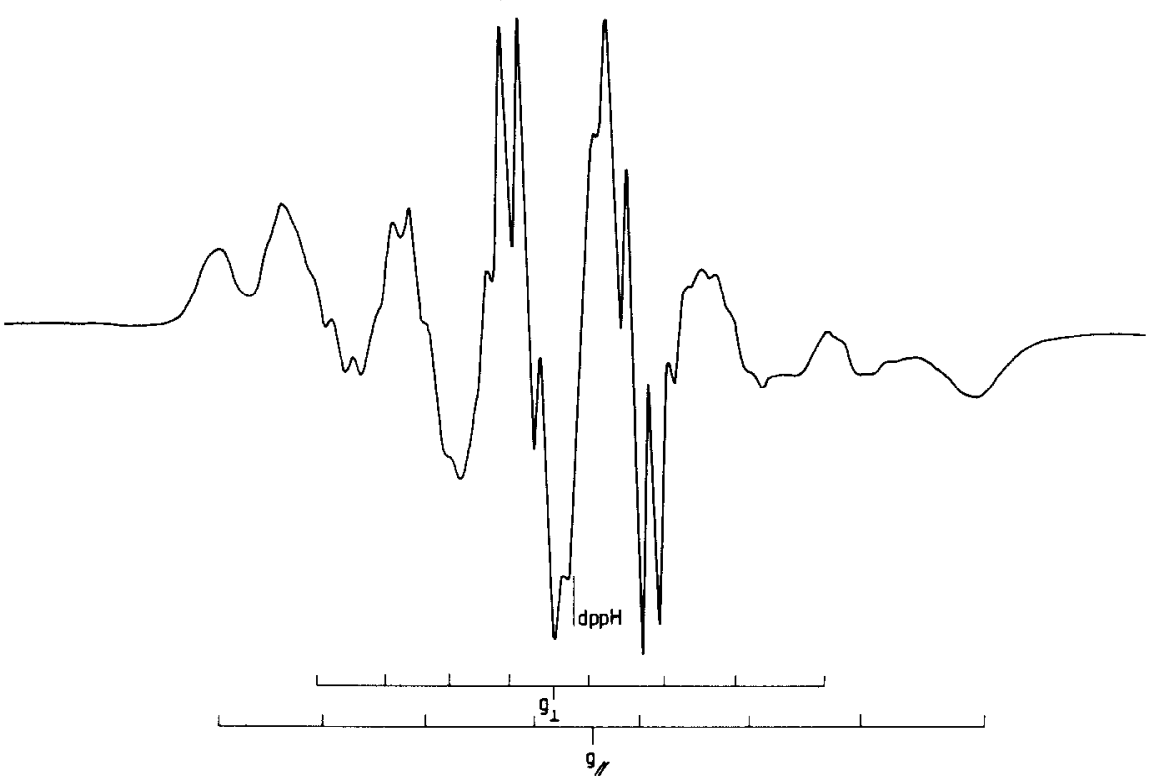

Fig. 1. X-band ESR spectrum at $77 \mathrm{~K}$ of $\mathrm{TaCl}_{2} \mathrm{H}_{2}$ (dmpe) $)_{2}$ in toluene.

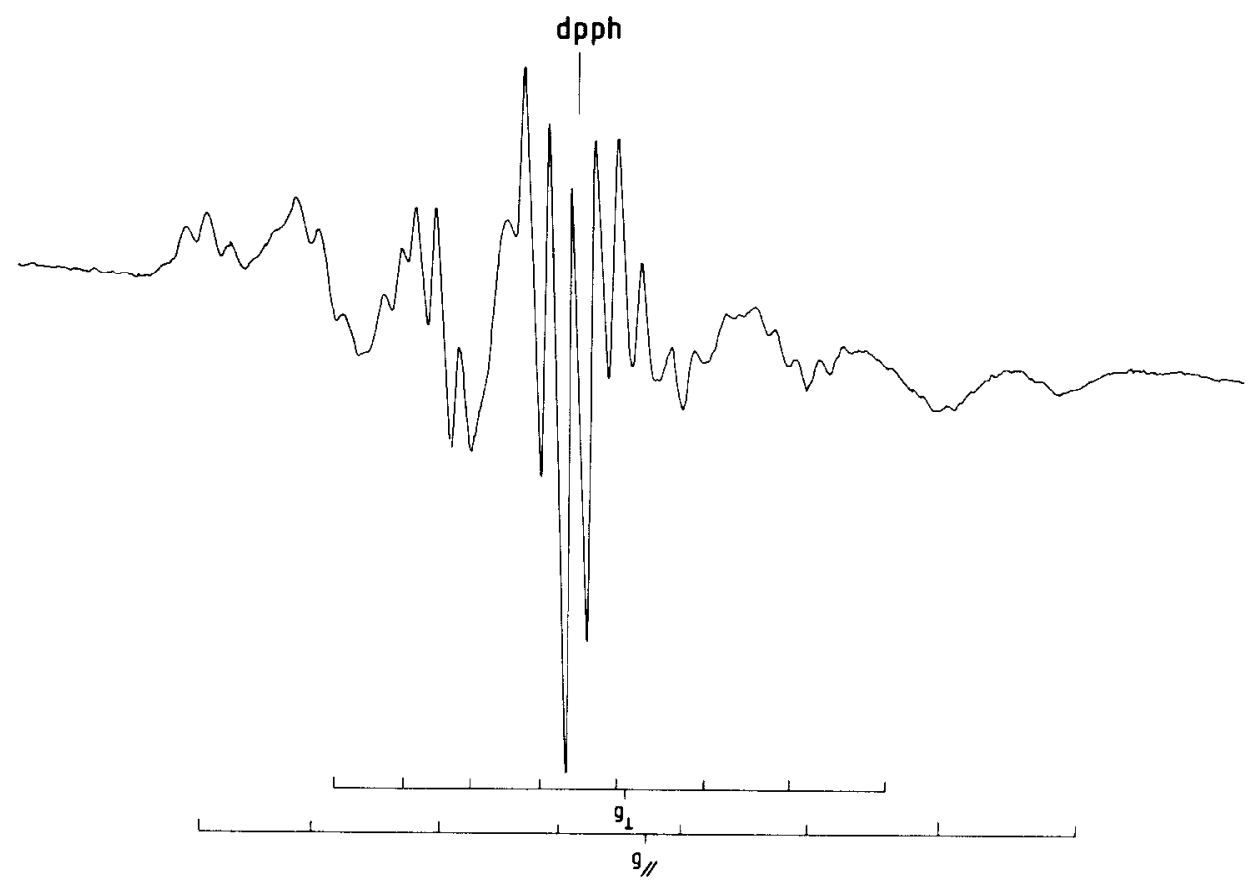

Fig. 2. X-band ESR spectrum at $77 \mathrm{~K}$ of $\mathrm{TaCl}_{2} \mathrm{H}_{2}\left(\mathrm{PMe}_{3}\right)_{4}$ in toluene.

fine coupling, suggests that the unpaired electron is in a $d_{x^{2}-y^{2}}$ orbital. For a $d^{1}$ ion with this ground state, the form of the $g$ and $A$ tensors will be $g_{\|} \leqslant$ $g_{\perp}<2$ and $\left|A_{\|}\right|>\left|A_{\perp}\right|$. The average value of $A_{\|}$ and $A_{\perp}$ is close to that found from fluid solution. Although $g_{\|}$and $A_{\|}$could be measured accurately, $g_{\downarrow}$ and $A_{\perp}$ could not. The multiplicity of lines arising from further coupling to ${ }^{31} \mathrm{P}$ may hide some splitting of the perpendicular features. For this reason, accurate spin density calculations were not thought worthwhile and their calculation was attempted only using the eqns.:

$$
\begin{aligned}
& A_{\|}=-P\left[K+\frac{4}{7}+\left(2-g_{\|}\right)+\frac{3}{7}\left(2-g_{\perp}\right)\right] \\
& A_{\perp}=-P\left[K-\frac{2}{7}+\frac{11}{14}\left(2-g_{\perp}\right)\right]
\end{aligned}
$$




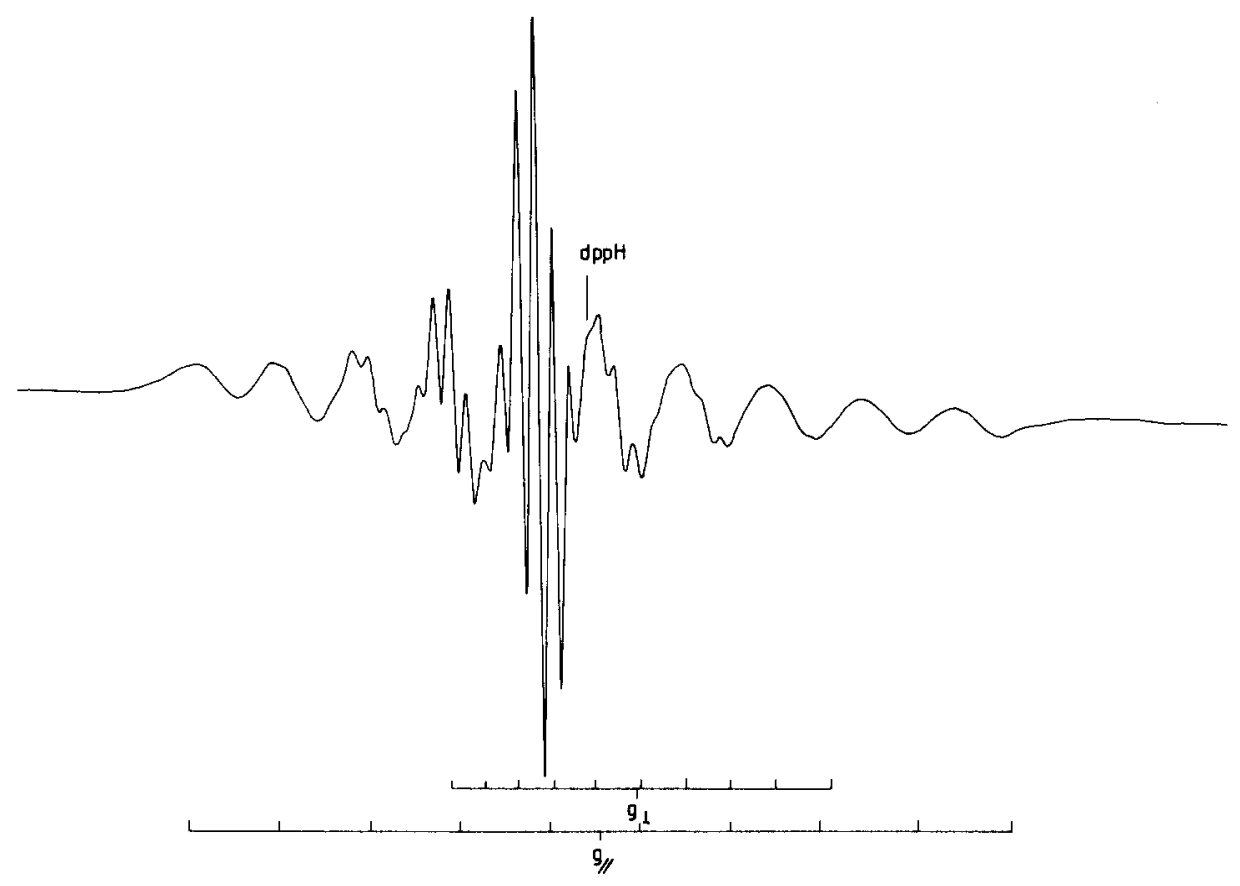

Fig. 3. X-band ESR spectrum at $77 \mathrm{~K}$ of $\mathrm{NbCl}_{2} \mathrm{H}_{2}(\mathrm{dmpe})_{2}$ in toluene.

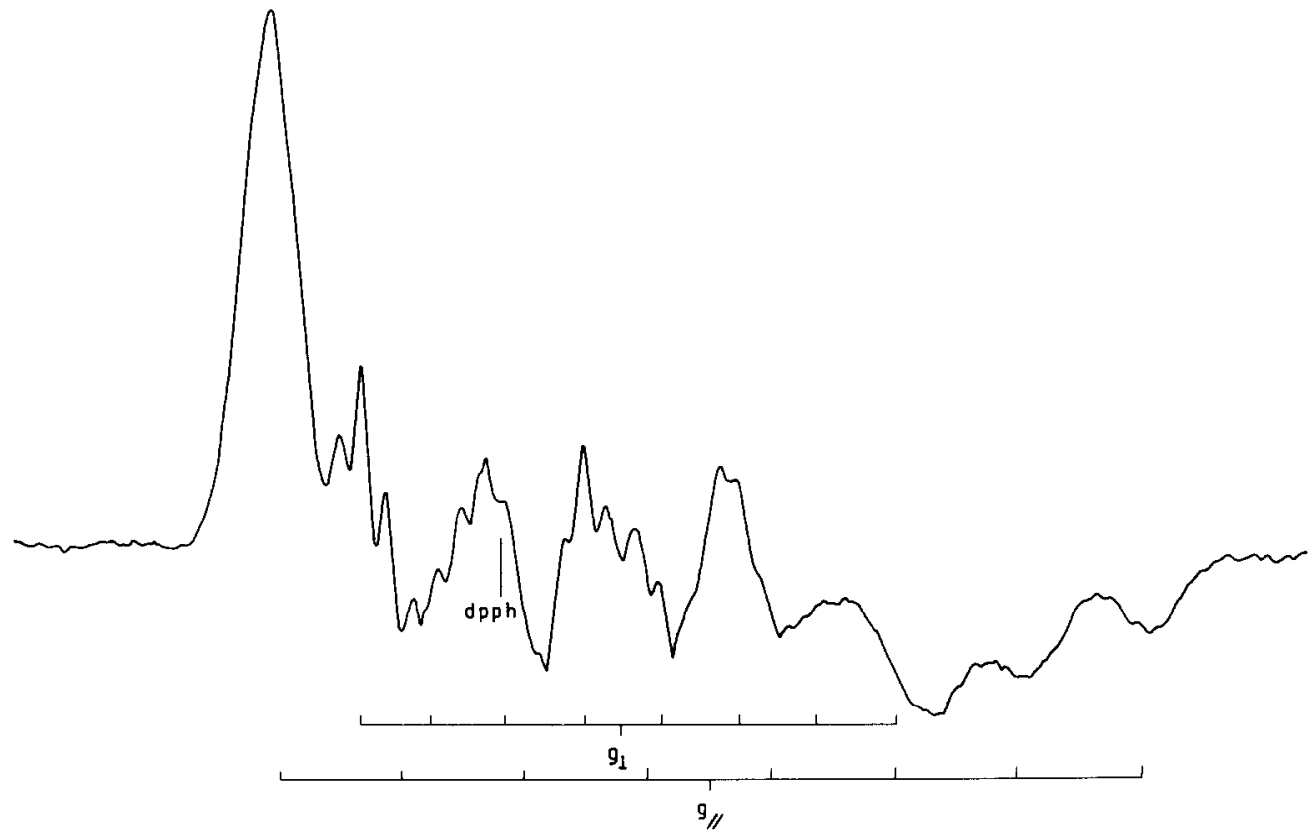

Fig. 4. Q-band ESR spectrum at $77 \mathrm{~K}$ of $\mathrm{TaCl}_{2} \mathrm{H}_{2}\left(\mathrm{PMe}_{3}\right)_{4}$ in toluene.

For $\mathrm{Ta}^{\circ}, P$ is known to be $0.0119 \mathrm{~cm}^{-1}, \mathrm{Nb}^{\circ}, P=$ 0.0136 and $\mathrm{Nb}^{3+}, P=0.0170$ [17] . It appears that no calculated values of $P$ for the $4+$ ions are known.

Analysis of the $g$ tensor for the niobium complex suggests the unpaired electron is in a $\mathrm{d}_{z^{2}}$ orbital. However, the pattern of metal h.f.s. shows that this cannot be the case, and the electron is essentially in a $d_{x^{2}-y^{2}}$ orbital. The large value of $g_{\|}$must arise from an ordering of the energy levels whose spacing is quite different from those of the tantalum complexes. This can easily happen in complexes which are in between the idealised dodecahedral $\left(D_{2 d}\right)$ and square antiprism $\left(D_{4 d}\right)$ structures. The crystal structure of the niobium complex has not been car- 


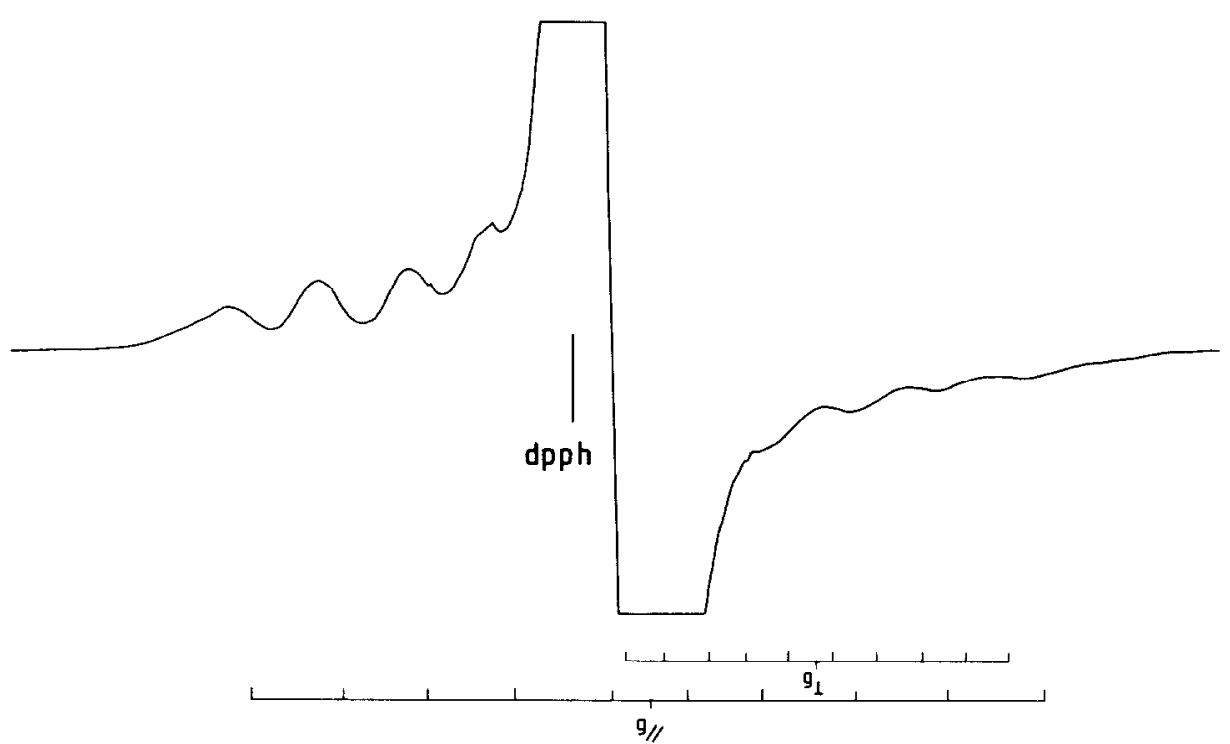

Fig. 5. Q-band ESR spectrum at $77 \mathrm{~K}$ of $\mathrm{NbCl}_{2} \mathrm{H}_{2}$ (dmpe) ${ }_{2}$ in toluene.

ried out, but $\mathrm{TaCl}_{2} \mathrm{H}_{2}\left(\mathrm{PMe}_{3}\right)_{4}$ is best described as distorted dodecahedral, [2] and that of $\mathrm{TaCl}_{2} \mathrm{H}_{2}$. $(\mathrm{dpme})_{2}$ as distorted square antiprism [3]. It is likely that the $g$ values in a frozen solution at $77 \mathrm{~K}$ could well average to a different value from fluid solution in which the structure can relax to an unstrained arrangement of ligands.

Iyperfine coupling to ${ }^{31} \mathrm{P}$ is close to that observed in fluid solution and shows the coupling is isotropic. No h.f.s. to $\mathrm{Cl}$ or ${ }^{1} \mathrm{H}$ was observed, and the frozen solution spectra of the deuterated samples were almost identical to the undeuterated materials. Calculation of metal spin densities cannot be carried out properly because the value of $P$ for the $4+$ ions is unknown. For the $\mathrm{Nb}$ complex, using the value of $P$ for $\mathrm{Nb}^{3+}$, then the $4 \mathrm{~d}$ population is $\mathrm{ca} .47 \%$. For the $\mathrm{Ta}$ complexes, using the value of $P$ for the $\mathrm{Ta}^{\circ}$ ion and increasing it to about 0.0150 as a reasonable estimate of the value of $P$ for $\mathrm{Ta}^{4+}$, then the $5 \mathrm{~d}$ populations are about $41 \%$ for $\mathrm{TaCl}_{2} \mathrm{H}_{2}(\mathrm{dmpe})_{2}$ and about $47 \%$ for $\mathrm{TaCl}_{2} \mathrm{H}_{2}\left(\mathrm{PMe}_{3}\right)_{4}$.

\section{Acknowledgements}

We thank the SERC for a grant for the spectrometers and Dr. J. F. Gibson for recording the Q-band spectra.

\section{References}

1 I. H. Elson, J. K. Kochi, U. Klabunde, L. E. Manzer, G. W. Parshall and F. N. Tebbe, J. Am. Chem. Soc., 96, 7374 (1974).

2 M. L. Luetkens, J. C. Huffman and A. P. Sattelberger, $J$. Am. Chem. Soc., IUS, 4474 (1983).

3 M. L. Luetkens, W. L. Elcesser, J. C. Huffman and A. P. Sattelberger,J. Chem. Soc., Chem. Commun., 1072 (1983)

4 M. L. Luetkens, W. L. Elcesser, J. C. Huffman and A. P. Sattelberger, Inorg. Chem., 23, 1718 (1984).

5 C. D. Garner, N. C. Howlader, F. E. Mabbs, A. T. McPhail, R. W. Miller and K. D. Onan, J. Chem. Soc., Dalton Trans., 1582 (1978)

6 D. Attanasio, C. Bellitto, A. Flamini and G. Pennesi, Inorg. Chem., 21, 1461 (1982).

7 D. Attanasio, C. Bellitto and A. Flamini, Inorg. Chem., $19,3419(1980)$.

8 D. Attanasio, C. Bellito, A. Flamini and G. Pennesi, Chem. Phys. Lett., 72, 307 (1980).

9 P. M. Kiernan, J. F. Gibson and W. P. Griffiths, J. Chem. Soc., Chem. Commun., 816 (1973).

10 R. A. Pribush and R. D. Archer, Inorg. Chem., 13, 2556 (1974).

11 B. R. McGarvey, Inorg. Chem., 5, 476 (1966).

12 R. G. Hayes, J. Chem. Phys., 44, 2210 (1966).

13 P. M. Kiernan, Inorg. Chim. Acta, 20, 89 (1976).

14 P. M. Kiernan and W. P. Griffith, J. Chem. Soc., Dalton Trans., 2489 (1975).

15 S. I. Weissman and C. S. Garner, J. Am. Chem. Soc., 78, 1072 (1956).

16 S. I. Weissman and M. Cohn, J. Chem. Phys., 27, 1440 (1957).

17 B. A. Goodman and J. B. Raynor, $A d v$. Inorg. Radiochem., 13, 135 (1970). 